\title{
Early life microbial exposure, child neurocognition and behaviour at 2 years of age: a birth cohort study
}

Elizabeth Senn ${ }^{\mathrm{a}, \mathrm{b}}$, Christos Symeonides $^{\mathrm{a}, \mathrm{c}}$, Peter Vuillermin ${ }^{\mathrm{a}, \mathrm{b}, \mathrm{d}}$ Anne-Louise Ponsonby ${ }^{\mathrm{a}, \mathrm{c}}$, the Barwon Infant Study Investigator Group

\section{Affiliations}

${ }^{a}$ Murdoch Children's Research Institute, Flemington Rd, Parkville, Victoria, 3052, Australia

${ }^{b}$ Deakin University, Geelong, Victoria 3220, Australia

${ }^{c}$ Department of Paediatrics, University of Melbourne, Grattan St Parkville, Victoria, 3052, Australia

d Barwon Health, University Hospital, Bellerine Street, Geelong, Victoria 3220, Australia

eJohn Carlin, Mimi Tang, Katie Allen, Fiona Collier, Terry Dwyer, Sarath Ranganathan and David

Burgner

\section{Correspondence}

Professor Anne-Louise Ponsonby, Molecular Epidemiology Research Group, Murdoch Children's

Research Institute, 50 Flemington Rd, Parkville, Vic. 3052, Australia; Fax +61 393481391

(email:anne-louise.ponsonby@mcri.edu.au).

\section{Declarations of interest}

The authors declare no completing financial interests

\section{Acknowledgements}

We thank the BIS participants for the generous contribution they have made to this project. We also thank current and past staff for their efforts in recruiting and maintaining the cohort and in

This is the author manuscript accepted for publication and has undergone full peer review but has not been through the copyediting, typesetting, pagination and proofreading process, which may lead to differences between this version and the Version of Record. Please cite this article as doi: $10.1111 /$ jpc.14695

This article is protected by copyright. All rights reserved. 
obtaining and processing the data and biospecimens. The establishment work and infrastructure for the BIS was provided by the Murdoch Children's Research Institute, Deakin University and Barwon Health. Subsequent funding was secured from the National Health and Medical Research Council of Australia (NHMRC) , The Shepherd Foundation, The Jack Brockhoff Foundation, the Scobie Trust, the Shane O'Brien Memorial Asthma Foundation, the OurWomen's Our Children's Fund Raising Committee Barwon Health, , the Rotary Club of Geelong, the Ilhan Food Allergy Foundation, GMHBA and the Percy Baxter Charitable Trust, Perpetual Trustees. In-kind support was provided by the Cotton On Foundation and CreativeForce. Research at Murdoch Children's Research Institute is supported by the Victorian Government's Operational Infrastructure Support Program. C. Symeonides is supported by a NHMRC PhD scholarship. A.L. Heffernan, J. F. Mueller, A.L. Ponsonby and P. Sly receive NHMRC fellowship support. ES is supported by Australian Rotary Health (Terry Orr Memorial Scholarship), Vanguard and Murdoch Children's Research Institute.

Abstract: Aim: To investigate the relationship between factors influencing external environmental microbial exposures (FEMEs), previously identified to be protective or to increase the risk of the development of allergic disease, and cognition and behaviour in infants 2 years of age in an Australian population.

Method: The Barwon Infant Study is a birth cohort $(n=1074)$ in Victoria, Australia. Comprehensive questionnaire, clinical and biological measures were collected at multiple time-points. Multiple linear regression was used to evaluate associations between 56 FEMEs and three outcomes; cognition (Bayley Scales of Infant and Toddler Development (BAYLEYIII)) ( $n=667$, mean (SD) age $=2.45(0.14)$ years), internalising and externalising behaviour (Child Behavior Checklist (CBCL)) ( $n=666$, mean(SD) age $=2.45$ (0.14)years). 
Results: Overall, there were no consistent patterns or dose response found within an outcome nor across all three outcomes, although there was some evidence for individual associations. Breastfeeding and child care were associated with higher cognitive scores (adj. mean diff. $[95 \% \mathrm{Cl}]=3.20[0.23,6.17]$ and $0.68[0.12,1.24]$ respectively), and increasing sibling number was associated with lower internalising behaviour (adj. mean diff. [95\% $\mathrm{Cl}]=-$ $4.13[-6.34,-1.91])$.

Conclusion: In contrast to allergic disease, there was an absence of epidemiological evidence to support the association between these FEMEs and cognition and behaviour. Direct investigations into the relationship between exposures which influence gut-microbial composition and cognition and behaviour are now needed.

Key words: microbiome; cognition; Bayley-III; internalising behaviour; externalising behaviour; Child Behaviour Checklist 


\section{Brief points}

\section{What is already known on this topic}

- $\quad$ Factors which influence external microbial exposures (FEMEs) such as pet ownership, antibiotic use and caesarean section have been identified as important factors in the development of allergic disease.

- $\quad$ Several of these factors impact the infant gut microbial composition.

- $\quad$ The gut microbiome also influences brain development and behaviour, however, the relationship between these factors and cognition and behaviour has not been well characterised.

\section{What this paper adds}

- $\quad$ This is the first epidemiological study to investigate relationship between a comprehensive range of both pre- and postnatal FEMEs and cognition and behaviour. 


\section{Introduction}

There is intense interest in the role of gut microbiome and early cognition and behaviour. Epidemiological studies have identified a range of early-life factors which influence external microbial exposures (termed FEMEs) that are associated with decreased allergic disease risk, some of which also influence the gut microbial composition. Yet little epidemiological work has been conducted on identifying if these factors also relate to infant cognition and behaviour.

The 'hygiene hypothesis' [1] emerged from the observation that larger household size was associated with decreased allergic disease. Subsequent work has shown that multiple factors which increase external microbial exposure are associated with reduced allergic disease, such as; antenatal exposure to farming environments [2] and antenatal pet ownership. Whereas, factors which reduce microbial exposure have been associated with increased allergic disease such as prenatal antibiotic use[3] and caesarean delivery [4].

There is evidence that some of these FEMEs also influence infant gut microbial composition, at least for; mode of delivery [5], antibiotic exposure [5] and pet ownership [6]. Gut microbes are thought to play a crucial role in allergic disease via immune programming and inflammatory mechanisms [7], although, the precise mechanisms remain unclear.

Evidence from germ-free mouse models suggests that the gut microbiome also modulates brain structure, function and behaviour via the microbiota-gut-brain axis [8]. Bacteria involved in the microbiota-gut-brain-axis are hypothesised to perform a more complex role than immune programming and inflammation alone and are thought to be also integral in metabolic, trophic, gene expression modification, protective and structural functions [8].

However, in contrast to allergic disease, there has been minimal investigation of the relationship between FEMEs and cognition and behaviour in humans. Findings from studies 
on the allergic disease cannot be extrapolated to cognition and behaviour as the bacteria are involved in different functions. To date, there has been no comprehensive investigation into the relationship between early-life FEMEs, particularly those identified as determinants of the gut microbiome, and cognition and behaviour in humans, although several studies into single candidate FEMEs have been undertaken, predominately investigating the role of mode of delivery on neurodevelopment [9].

Here we undertake an extensive investigation of over 50 FEMEs across the antenatal and postnatal period and their association with infant cognition and internalising and externalising behaviour at 2 years of age. These factors were selected based on past work indicating variation in allergic disease risk. Some factors have been shown to also impact on the gut microbiome. By using this systematic approach, we aim to; investigate a particular factor's influence on an outcome, identify any patterns across the three outcomes, identify any patterns relating to time of exposure and to be able to compare and contrast these findings with those from allergic disease.

\section{Materials and Methods}

\section{The Cohort}

The Barwon Infant Study (BIS) is an unselected antenatal sampling frame birth cohort study $(n=1,074)$ with antenatal recruitment south-west of Melbourne, Victoria [10].

\section{The Cohort sample}

Women were recruited by 28 weeks gestation between June 2010 and June 2013 using an unselected sampling frame. Population characteristics and exclusion criteria have been previously described [10]. This report is based on infants who completed the BAYLEYIII or Child Behaviour Check List (CBCL) at 2 years of age (Figure 1). Multiple births were excluded.

\section{Measures}




\section{Exposures}

Comprehensive questionnaire data (including sociodemographic profile, life environment, perinatal associated measures and child care attendance) and an extensive range of clinical measures were collected antenatally and at birth, 4 weeks, 3, 6, 9, 12 and 18 months and 2 years [10]. When the same variable was collected at different time points, each time point was considered a separate factor (e.g. maternal antibiotic use in trimesters 1, 2 and 3 was considered as 3 separate factors).

\section{Outcome measures}

Cognitive measure

Bayley Scales of Infant and Toddler Development 3rd edition (BAYLEY-III)

The BAYLEY-III[11] cognitive domain was used to measure cognition. The BAYLEY-III was administered at the 2-year review and scored by trained personnel.

Age-standardised cognitive composite scores have a mean score of 100 (SD =15) [11]. The standardised sample included children with developmental delay (approximately $10 \%)$, which had the effect of lowering the overall mean score. Indeed, healthy term Australian children were found have a significantly higher mean score [12]. As we similarly observed a residual age at assessment for the composite scores, we adjusted for the raw scores for post-conceptional age, the age parameter most related to cognition in this cohort. Note in doing this, we are unable to compare the cognitive ability of our cohort with other age-matched cohorts as they used the cognitive composite scores. This was determined to be unimportant as the objective of this study was to investigate the linear relationship between factors influencing FEMEs and cognition and not the cognitive ability of our cohort. The maximum obtainable score is 91 .

Behavioural measures

Child Behaviour Checklist (CBCL) 
The CBCL /1.5-5[13] internalising and externalising problem scales were used to measure behaviour[13]. T-scores were used in our analysis and have a mean of 50 (SD = 10). Higher scores indicate greater problems. T-scores $60 \geq 63$ represent borderline scores and T-scores $>63$ fall into the clinical range. The $C B C L$ questionnaire was collected at the 2year interview in conjunction with the BAYLEY-III assessment. The CBCL was completed by the infant's carer.

\section{Statistical analysis}

Infant and family characteristics are presented as mean (SD) or percentages for those who completed either the BAYLEY-III or the CBCL or both (Table 1). T-tests were used to determine mean differences of continuous variables between the inception cohort and BAYLEY-III/CBCL, while Fisher exact test was used to determine differences in proportions of the categorical variables. Non-parametric tests were used where appropriate. Multiple linear regression was used to evaluate associations between the FEMEs and each outcome (cognition, internalising and externalising behaviour) (Table 2; Note that null associations are recorded at the bottom of the table). Significance is reported at the $5 \%$ level. Levels of all external microbial exposures (for example, disinfectant use) were ordered so that the reference group was the level that had the least microbial exposure (e.g. 'everyday') to most microbial exposure (e.g. 'don't use') (Table 2). Ordering in this manner was undertaken to investigate possible dose response effects, similar to those undertaken in studies in allergic disease. No adjustments for multiple comparisons were undertaken to reduce the risk of type II errors [14]. Stata 15.0 software (StataCorp, College Station, TX) was used for all analyses.

\section{Confounder selection}

As the purpose of this study was to screen for preliminary associations only, fully adjusted models are beyond the scope of this paper. All analyses were adjusted for post- 
conceptional age and child sex. The cognitive analyses were also adjusted for the processing factors, researcher and researcher experience, which were shown to independently influence the cognitive measure in our cohort.

\section{Ethics}

BIS was approved by the Barwon Health Ethics Committee (BHEC 10/24) with informed, written consent obtained from the parents or guardians.

\section{Results}

\section{Study populations}

The majority of infants in both cohorts were full-term, vaginally-born, and born to Australian-born parents. The mean (SD) age at interview for both the cognitive and $\mathrm{CBCL}$ cohort was $2.46(0.14)$ years (Table 1$)$. Mothers of infants with BAYLEY-III and CBCL data were marginally older, more likely to have a degree-level education and smoked less than those in the inception cohort. Infants with BAYLEY-III data were breast-fed longer and received more antibiotics than the inception cohort. Less behavioural symptoms were reported on the $\mathrm{CBCL}$ than expected from $\mathrm{CBCL}$ normative data (Table 1).

\section{Results}

Although there were some individual associations (reported below), no consistent patterns of associations or dose response were found within an outcome nor across the three outcomes. Futhermore, no time period appeared more important than any other.

\section{Antenatal period}

Maternal antibiotic use in trimester 1 , but not trimester 2 or 3 , was associated with reduced externalising behaviour (Table 2 ).

There was an inverse association with the frequency of disinfectant use in T1 and T3 and cognitive scores (Table 2). 
Having any older siblings at birth was inversely associated with cognitive scores at 2 years, but positively associated with lower internalising behaviour (Table 2).

\section{Birth}

Exposure to labour expressed was associated with higher internalising behaviour compared to infants born to mothers who underwent scheduled C-section (Table 2).

\section{Postnatal Period}

Infants who received any breastmilk had higher cognitive scores than infants who received no breastmilk and the longer the infant breastfed, the higher the cognitive scores (Table 2).

Postnatal antibiotic use only between 3 to 6 months was associated with reduced internalising behaviour (Table 2).

Reduced infant hand washing frequency was associated with reduced internalising behaviour, however, evidence was weak (Table 2). A reversal of this relationship was seen at $12 \mathrm{~m}$, with reduced infant hand washing frequency associated with increased internalising behaviour (Table 2).

Reduced infant bathing frequency at 6 months was associated with lower cognitive scores and higher externalising behaviour when compared to those infants who were bathed once or more times per day (Table 2).

Dummy use at 4 weeks, 6 or 12 months was associated with lower cognitive scores (Table 2). Length of dummy use (hours) at 4 weeks was also associated with lower cognitive scores. Using the mother's mouth to clean the dummy was associated with higher internalising scores at 4 weeks and 6 months (Table 2).

Childcare attendance was associated with higher cognitive performance than children who did not receive any childcare before the age of 1 , although the effect size was small (Table 2). 
Hygiene scores

We examined composite hygiene patterns based on the ALSPAC score [15] at 4 weeks, 6 and 12 months, but clear patterns were not detected.

\section{Discussion}

Factors altering early life external microbial exposure have been shown to be important in allergic disease programming. The intention of this study was to investigate whether environmental factors previously associated with allergic diseases were also associated with cognition and behavioural outcomes at 2 years of age. Factors also previously linked to gut microbiome were of key interest. In particular, we focused on investigating the strength of a particular factor's influence on individual outcomes, identifying any patterns across the three outcomes, identifying any patterns relating to time of exposure and comparing and contrasting these findings with those from allergic disease.

\section{A factor's influence on an outcome}

As expected, breastfeeding was the strongest predictor for cognition, followed by disinfectant use in T3, siblings and weak associations for dummy use bathing frequency and child care attendance. Antenatal disinfectant use at different time periods had the strongest association with both internalising and externalising behaviour. Whereas expected factors, such as siblings and antibiotic use had less influence. No dose response was found with any factor.

Patterns across the three outcomes

In Table 2, although there was perhaps slightly more evidence of associations than expected by chance ( $20 \%$ with $p<$ or $=0.05$ compared to the expected $5 \%)$, there were no clear and consistent patterns of association between factors associated with FEMEs and any 
outcome. Further, only the association between the number of siblings and the two outcome cognition and internalising behaviour, would have survived Bonferroni correction.

Time of exposure

Multiple time points for multiple variables were investigated. No time point seemed more significant than any other.

Compare and contrast these findings with those from allergic disease.

Unlike studies from asthma and allergy we did not observe an overall pattern that a more sterile environment lead to more adverse outcomes. Indeed, the direction of some associations were opposite to that expected if a more sterile environment is associated with adverse cognitive and behavioural outcomes, such as vaginal delivery and higher internalising behaviour.

Additionally, there were a number of important null findings. Despite dog ownership being associated with reduce allergic disease in both our[16] and a nearby[17] cohorts, dog ownership did not relate to cognition or behaviour. Also, no clear associations were evident with livestock ownership and C-section. Moreover, no consistent associations were found with maternal antibiotic use. Notably, several of these factors have been linked to the gut microbiome.

In contrast to the educative role bacteria play in the immune system where exposure to a greater range of microbes increases the ability of the immune system to be able to distinguish who is friend and who is foe[18] , the role bacteria play in the microbiota-gutbrain axis is more diverse and complex [8]. Different patterns of association have been observed in both animal and human studies. Higher alpha diversity has been associated with lower overall cognitive scores in human 2 year-olds [19]. Additionally, mice who have been 
treated with antibiotics display reduced microbial diversity, reduced anxiety and increased exploratory behaviour in open spaces [20]. It is likely relationships between FEMEs and cognition and behaviour are non-monotonic. As brain development is multifactorial and intertwined with social influences, future studies teasing out microbial influences from social influences are warranted.

Despite the lack of association between FEMEs and cognition and behavioural outcomes found in this study, the gut microbiome may still play a significant role in cognition and behaviour[21]. Firstly, FEMEs are likely to only explain a small portion of the microbiome variation. Secondly, we only studied FEMEs previously shown to alter allergic disease risk. It may be that other environmental and lifestyle factors that are known to influence brain function and structure and microbiome composition, such as exercise [22], stress [23] or diet [24] are more important for cognition and behaviour than those found to be important for immune programming.

This study's strength is that it is the first epidemiological study to investigate associations between a comprehensive range of early-life FEMEs and three outcomes: cognition, internalising and externalising behaviour, from a population-derived cohort. There are several limitations to this study. Firstly, as our cohort is an unselected sample, it may not be representative of all mothers and live births. Secondly, as the purpose of this study was to screen for preliminary associations only, models were not fully adjusted and multiple corrections were not applied in order to consider each association on its own [14]. Additionally, many of the reference groups have low numbers. Exposures were analysed in this manner, instead of using a reference group with the highest numbers in order to 
investigate a dose-response effect and for consistency with past allergy papers.

Furthermore, we recognise that the relationships may be non-monotonic, however, nonmonotonic investigations are beyond the scope of this paper. Lastly, our cohort reported less behavioural symptoms than expected based on normative data[13]. There may not be sufficient variation in either the levels of exposure or in the levels of cognition or behaviour in our cohort, limiting our ability to detect associations. Further work would ideally assess trajectories rather than outcomes at a single time point.

\section{Conclusion}

Overall there was no consistent pattern across the FEMEs and cognition and behaviour at 2 years of age. In contrast to allergic disease, there was no evidence that markers associated with a more sterile early environment increase neurodevelopmental risk. Direct investigations into gut microbiome compositional differences and cognition and behaviour in humans are now necessary to determine the role the gut microbiome plays in brain function and development. 


\section{References}

[1]. Strachan DP. Hay fever, hygiene, and household size. BMJ: British Medical Journal. 1989;299(6710):1259.

[2]. Ege MJ, Bieli C, Frei R, van Strien RT, Riedler J, Üblagger E, et al. Prenatal farm exposure is related to the expression of receptors of the innate immunity and to atopic sensitization in school-age children. Journal of Allergy and Clinical Immunology. 2006;117(4):817-23.

[3]. Stensballe LG, Simonsen J, Jensen SM, Bønnelykke K, Bisgaard H. Use of antibiotics during pregnancy increases the risk of asthma in early childhood. The Journal of pediatrics. 2013;162(4):832-8. e3.

[4]. Bager P, Wohlfahrt J, Westergaard T. Caesarean delivery and risk of atopy and allergic disesase: meta - analyses. Clinical \& Experimental Allergy. 2008;38(4):634-42.

[5]. Bokulich NA, Chung J, Battaglia T, Henderson N, Jay M, Li H, et al. Antibiotics, birth mode, and diet shape microbiome maturation during early life. Science Translational Medicine. 2016;8(343):343ra82-ra82.

[6]. Azad MB, Konya T, Maughan H, Guttman DS, Field CJ, Sears MR, et al. Infant gut microbiota and the hygiene hypothesis of allergic disease: impact of household pets and siblings on microbiota composition and diversity. Allergy, Asthma \& Clinical Immunology. 2013;9(1):15.

[7]. McDade TW, Rutherford J, Adair L, Kuzawa CW. Early origins of inflammation: microbial exposures in infancy predict lower levels of C-reactive protein in adulthood. Proceedings of the Royal Society of London B: Biological Sciences. 2010;277(1684):112937.

[8]. Cryan JF, Dinan TG. Mind-altering microorganisms: the impact of the gut microbiota on brain and behaviour. Nature reviews neuroscience. 2012;13(10):701.

[9]. Curran EA, O'neill SM, Cryan JF, Kenny LC, Dinan TG, Khashan AS, et al. Research review: birth by caesarean section and development of autism spectrum disorder and attention - deficit/hyperactivity disorder: a systematic review and meta - analysis. Journal of Child Psychology and Psychiatry. 2015;56(5):500-8.

[10]. Vuillermin P, Saffery R, Allen KJ, Carlin JB, Tang MLK, Ranganathan S, et al. Cohort Profile: The Barwon Infant Study. International Journal Of Epidemiology. 2015;44(4):1148-60.

[11]. Bayley N. Bayley scales of infant and toddler development: Bayley-III: Harcourt Assessment, Psych. Corporation San Antonio, TX; 2006.

[12]. Anderson PJ, De Luca CR, Hutchinson E, Roberts G, Doyle LW. Underestimation of developmental delay by the new Bayley-III Scale. Archives of pediatrics \& adolescent medicine. 2010;164(4):352-6.

[13]. Achenbach TM, Rescorla LA. Manual for the ASEBA preschool forms and profiles : an integrated system of multi-informant assessment; child behavior checklist for ages 1 1/2-5; language development survey; caregiver - teacher report form. Burlington, Vt.: ASEBA; 2008.

[14]. Rothman KJ. No adjustments are needed for multiple comparisons. Epidemiology (Cambridge, Mass). 1990;1(1):43-6. 
[15]. Sherriff A, Golding J, Team AS. Factors associated with different hygiene practices in the homes of 15 month old infants. Archives of disease in childhood. 2002;87(1):30-5.

[16]. Molloy J, Koplin J, Allen K, Tang M, Collier F, Carlin J, et al. Vitamin D insufficiency in the first 6 months of infancy and challenge - proven IgE - mediated food allergy at 1 year of age: a case - cohort study. Allergy. 2017;72(8):1222-31.

[17]. J. KJ, C. DS, A.-L. P, K. TML, J. LA, C. GL, et al. Environmental and demographic risk factors for egg allergy in a population-based study of infants. Allergy. 2012;67(11):141522.

[18]. Lathrop SK, Bloom SM, Rao SM, Nutsch K, Lio CW, Santacruz N, et al. Peripheral education of the immune system by colonic commensal microbiota. Nature.

2011;478(7368):250-4.

[19]. Carlson AL, Xia K, Azcarate-Peril MA, Goldman BD, Ahn M, Styner MA, et al. Infant Gut Microbiome Associated With Cognitive Development. Biological Psychiatry. 2018;83(2):148-59.

[20]. Bercik P, Denou E, Collins J, Jackson W, Lu J, Jury J, et al. The Intestinal Microbiota Affect Central Levels of Brain-Derived Neurotropic Factor and Behavior in Mice.

Gastroenterology. 2011;141(2):599-609.e3.

[21]. Altman DG, Bland JM. Absence of evidence is not evidence of absence. Bmj. 1995;311(7003):485.

[22]. Robinson AM, Bucci DJ. Maternal Exercise and Cognitive Functions of the Offspring. Cognitive sciences. 2012;7(2):187-205.

[23]. Jasarevic E, Howerton CL, Howard CD, Bale TL. Alterations in the Vaginal Microbiome by Maternal Stress Are Associated With Metabolic Reprogramming of the Offspring Gut and Brain. Endocrinology. 2015;156(9):3265-76.

[24]. Kang SS, Jeraldo PR, Kurti A, Miller MEB, Cook MD, Whitlock K, et al. Diet and exercise orthogonally alter the gut microbiome and reveal independent associations with anxiety and cognition. Molecular Neurodegeneration. 2014;9(1):36.

\section{Figures and Tables}

Figure 1: Flow chart of the participating mother-infant dyads in the initial cohort, BIII and CBCL sample (adapted from [10]).

Table 1: Characteristics of the participants who completed the measure(s). Infant and family characteristics are presented as mean (SD) or $\mathrm{n}$ (percentages) for those who completed either the BAYLEY-III ( $n=667)$ or the CBCL $(n=666)$.

Table 2: The relationship between the external microbial exposures and cognition and behaviour 


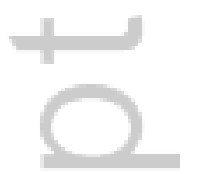




\section{Early life microbial exposure, child neurocognition and behaviour at $\mathbf{2}$ years of age: a birth cohort study}

Elizabeth Senn ${ }^{\mathrm{a}, \mathrm{b}}$, Christos Symeonides $^{\mathrm{a}, \mathrm{c}}$, Peter Vuillermin ${ }^{\mathrm{a}, \mathrm{b}, \mathrm{d}}$ Anne-Louise Ponsonby ${ }^{\mathrm{a}, \mathrm{c}}$, the Barwon Infant Study Investigator Group

\section{Affiliations}

${ }^{a}$ Murdoch Children's Research Institute, Flemington Rd, Parkville, Victoria, 3052, Australia

${ }^{b}$ Deakin University, Geelong, Victoria 3220, Australia

${ }^{c}$ Department of Paediatrics, University of Melbourne, Grattan St Parkville, Victoria, 3052, Australia

d Barwon Health, University Hospital, Bellerine Street, Geelong, Victoria 3220, Australia

eJohn Carlin, Mimi Tang, Katie Allen, Fiona Collier, Terry Dwyer, Sarath Ranganathan and David

Burgner

\section{Correspondence}

Professor Anne-Louise Ponsonby, Molecular Epidemiology Research Group, Murdoch Children's

Research Institute, 50 Flemington Rd, Parkville, Vic. 3052, Australia; Fax +61 393481391

(email:anne-louise.ponsonby@mcri.edu.au).

\section{Declarations of interest}

The authors declare no completing financial interests

\section{Acknowledgements}

We thank the BIS participants for the generous contribution they have made to this project. We also thank current and past staff for their efforts in recruiting and maintaining the cohort and in obtaining and processing the data and biospecimens. The establishment work and infrastructure for the BIS was provided by the Murdoch Children's Research Institute, Deakin University and Barwon Health. Subsequent funding was secured from the National Health and Medical Research Council of 
Australia (NHMRC) , The Shepherd Foundation, The Jack Brockhoff Foundation, the Scobie Trust, the Shane O'Brien Memorial Asthma Foundation, the OurWomen's Our Children's Fund Raising Committee Barwon Health, , the Rotary Club of Geelong, the Ilhan Food Allergy Foundation, GMHBA and the Percy Baxter Charitable Trust, Perpetual Trustees. In-kind support was provided by the Cotton On Foundation and CreativeForce. Research at Murdoch Children's Research Institute is supported by the Victorian Government's Operational Infrastructure Support Program. C. Symeonides is supported by a NHMRC PhD scholarship. A.L. Heffernan, J. F. Mueller, A.L. Ponsonby and P. Sly receive NHMRC fellowship support. ES is supported by Australian Rotary Health (Terry Orr Memorial Scholarship), Vanguard and Murdoch Children's Research Institute. 


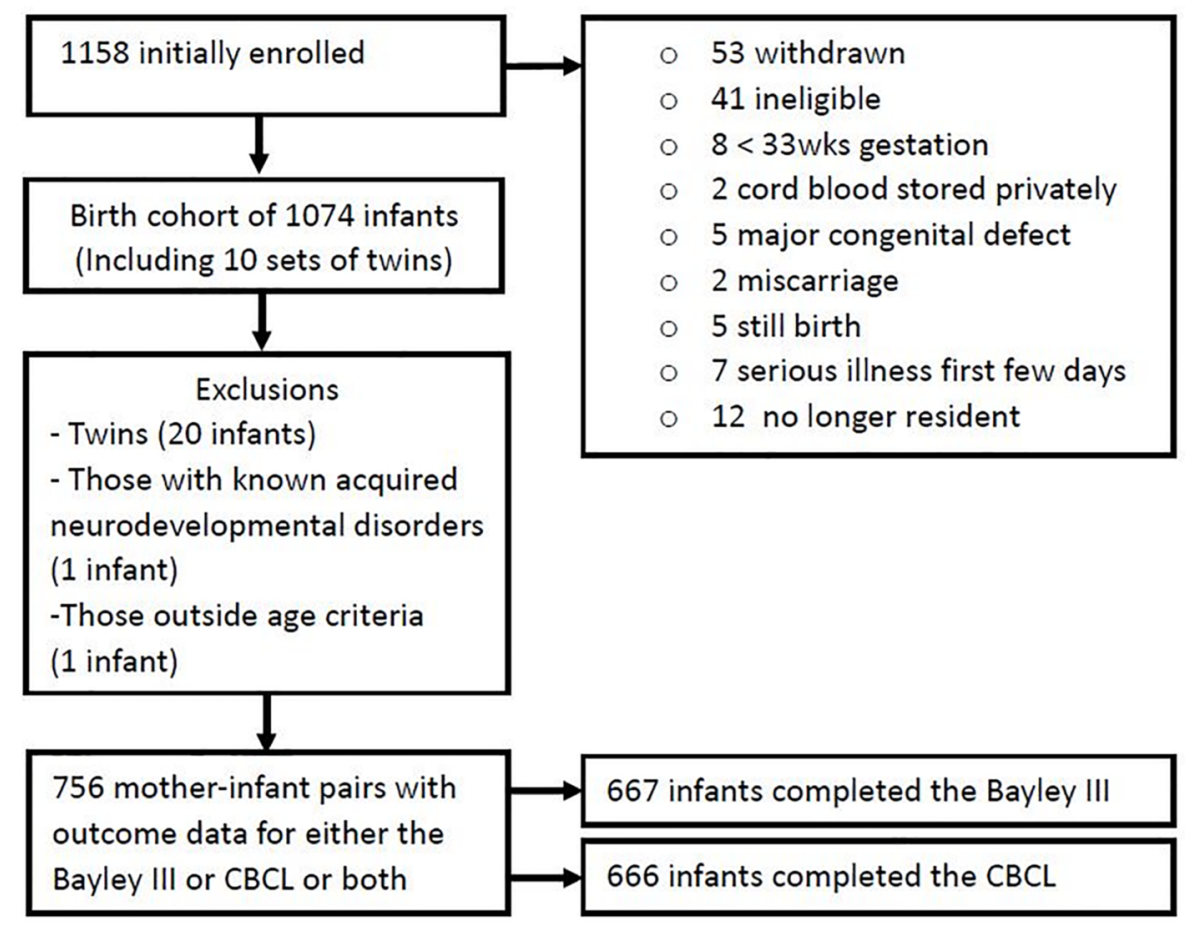

JPC_14695_Figure 1. Flow chart_tiff (400dpi).tif 
Table 1: Comparison between the characteristics of the inception cohort with those participants who completed the cognitive and behavioural measures

\begin{tabular}{|c|c|c|c|}
\hline Characteristics & $\begin{array}{r}\text { Inception } \\
(n=1074)\end{array}$ & $\begin{array}{c}\text { Bayley-III } \\
(n=667)\end{array}$ & $\begin{array}{c}C B C L \\
(n=666)\end{array}$ \\
\hline \multicolumn{4}{|l|}{ Parent and household } \\
\hline Maternal age at conception (years)(mean(SD)) & $31.33(4.79)$ & 31.95(4.57) & $32.04(4.36)$ \\
\hline Paternal age at conception (years)(mean(SD)) & $33.49(5.85)$ & $33.73(5.62)$ & $33.97(5.42)$ \\
\hline Maternal education (uni degree or above) & $548(51.31 \%)$ & $391(58.89 \%)$ & $401(60.39 \%)$ \\
\hline Paternal education (uni degree or above) & $367(35.15 \%)$ & $253(38.98 \%)$ & $260(40 \%)$ \\
\hline Paternal full-time employment & $945(91.75 \%)$ & $586(91.14 \%)$ & $588(91.45 \%)$ \\
\hline \multicolumn{4}{|l|}{ Socioeconomic index for area (SEIFA) } \\
\hline low & $357(33.65 \%)$ & $200(30.35 \%)$ & 192(29.14\%) \\
\hline middle & $353(33.27 \%)$ & $226(34.29 \%)$ & $234(35.51 \%)$ \\
\hline high & $351(33.08 \%)$ & $233(35.36 \%)$ & $233(35.36 \%)$ \\
\hline Mother born in Australia & $967(90.21 \%)$ & $599(89.81 \%)$ & $600(90.09 \%)$ \\
\hline Both parents born in Australia & $852(82.08 \%)$ & $527(81.58 \%)$ & $531(81.94 \%)$ \\
\hline Single parental status in pregnancy & $43(4.01 \%)$ & $21(3.15 \%)$ & $18(2.7 \%)$ \\
\hline \multicolumn{4}{|l|}{ Number of older siblings in the same house at T1T2 } \\
\hline None & $483(45.01 \%)$ & $303(45.5 \%)$ & $297(44.66 \%)$ \\
\hline One & $374(34.86 \%)$ & $239(35.89 \%)$ & 239(35.94\%) \\
\hline Two & $177(16.5 \%)$ & $102(15.32 \%)$ & $111(16.69 \%)$ \\
\hline Three & $34(3.17 \%)$ & $18(2.7 \%)$ & $16(2.41 \%)$ \\
\hline Four & $3(0.28 \%)$ & $2(0.3 \%)$ & $1(0.15 \%)$ \\
\hline Five & $1(0.09 \%)$ & $1(0.15 \%)$ & 0 \\
\hline Six & $1(0.09 \%)$ & $1(0.15 \%)$ & $1(0.15 \%)$ \\
\hline English - main language at home at $12 \mathrm{~m}$ & $863(97.96 \%)$ & $632(98.6 \%)$ & $635(98.76 \%)$ \\
\hline \multicolumn{4}{|l|}{ Pregnancy } \\
\hline Maternal smoking at preconception or in T1 & $166(15.65 \%)$ & 75(11.33\%) & 75(11.31\%) \\
\hline Any maternal smoking in $\mathrm{T} 2$ or $\mathrm{T} 3$ & $68(6.4 \%)$ & $24(3.61 \%)$ & $25(3.77 \%)$ \\
\hline Any maternal antibiotic use in pregnancy & $180(16.84 \%)$ & $116(17.42 \%)$ & $111(16.69 \%)$ \\
\hline Maternal pet ownership & $788(73.78 \%)$ & $488(73.38 \%)$ & $473(71.23 \%)$ \\
\hline Maternal dog ownership & $595(68 \%)$ & $368(67.52 \%)$ & $361(65.4 \%)$ \\
\hline Maternal livestock ownership & $73(6.9 \%)$ & $50(7.59 \%)$ & $46(6.98 \%)$ \\
\hline GBS status & $212(21.03 \%)$ & $133(21.01 \%)$ & $136(21.48 \%)$ \\
\hline \multicolumn{4}{|l|}{ Birth } \\
\hline Gestation age (completed weeks) (mean(SD)) & $39.44(1.52)$ & $39.49(1.46)$ & $39.49(1.45)$ \\
\hline \multicolumn{4}{|l|}{ Prematurity } \\
\hline Pre-term $<34$ & $6(0.56 \%)$ & $4(0.6 \%)$ & $4(0.6 \%)$ \\
\hline Late pre-term $\geq 34<37$ & $41(3.82 \%)$ & $21(3.15 \%)$ & $22(3.3 \%)$ \\
\hline Term $\geq 37<42$ & $1027(95.62 \%)$ & $642(96.25 \%)$ & $640(96.1 \%)$ \\
\hline \multicolumn{4}{|l|}{ Mode of birth } \\
\hline Unassisted vaginal birth & $525(48.88 \%)$ & $320(47.98 \%)$ & $318(47.75 \%)$ \\
\hline Forceps & $91(8.47 \%)$ & $58(8.7 \%)$ & $58(8.71 \%)$ \\
\hline Vacuum & $123(11.45 \%)$ & $84(12.59 \%)$ & $83(12.46 \%)$ \\
\hline
\end{tabular}

This article is protected by copyright. All rights reserved. 


\begin{tabular}{|c|c|c|c|}
\hline Emergency Caesarean Section & 179(16.67\%) & 104(15.59\%) & $111(16.67 \%)$ \\
\hline Elective Caesarean Section & $156(14.53 \%)$ & $101(15.14 \%)$ & $96(14.41 \%)$ \\
\hline Birthweight (kg)(mean (SD)) & $3.53(0.52)$ & $3.56(0.5)$ & $3.58(0.49)$ \\
\hline \multicolumn{4}{|l|}{ Birthweight } \\
\hline low birthweight $<2500 \mathrm{~g}$ & $32(2.99 \%)$ & $13(1.95 \%)$ & $11(1.65 \%)$ \\
\hline typical birthweight $\geq 2500<4200 \mathrm{~g}$ & $946(88.33 \%)$ & $598(89.66 \%)$ & $601(90.24 \%)$ \\
\hline high birthweight $\geq 4200 \mathrm{~g}$ & $93(8.68 \%)$ & $56(8.4 \%)$ & $54(8.11 \%)$ \\
\hline \multicolumn{4}{|l|}{ Apgar at $5 \mathrm{~min}$} \\
\hline$<7$ & $25(2.38 \%)$ & $13(2 \%)$ & $15(2.31 \%)$ \\
\hline$\geq 7$ & $1024(97.62 \%)$ & $638(98 \%)$ & $635(97.69 \%)$ \\
\hline \multicolumn{4}{|l|}{ Child } \\
\hline Infant sex (female) & $519(48.32 \%)$ & $306(45.88 \%)$ & $313(47 \%)$ \\
\hline Breastfeeding (weeks)(mean(SD)) & $31.49(20.02)$ & 34.13(19.23) & 34.3(19.07) \\
\hline \multicolumn{4}{|l|}{ Duration of breastfeeding in the first $12 \mathrm{~m}$} \\
\hline None & $22(2.28 \%)$ & $6(0.91 \%)$ & $10(1.52 \%)$ \\
\hline Any breastmilk feeding $>0<1 \mathrm{wk}$ & $113(11.7 \%)$ & $58(8.77 \%)$ & $58(8.81 \%)$ \\
\hline Any breastmilk feeding $\geq 1 \mathrm{wk}<6 \mathrm{~m}$ & $255(26.4 \%)$ & $168(25.42 \%)$ & $158(24.01 \%)$ \\
\hline Any breastmilk feeding $\geq 6 \mathrm{~m}<12 \mathrm{~m}$ & $210(21.74 \%)$ & $145(21.94 \%)$ & $152(23.1 \%)$ \\
\hline Any breastmilk feeding $\geq 12 \mathrm{~m}$ & $366(37.89 \%)$ & 284(42.97\%) & $280(42.55 \%)$ \\
\hline Postnatal antibiotic use in the first $12 \mathrm{~m}$ & $439(40.88 \%)$ & $308(46.18 \%)$ & $302(45.35 \%)$ \\
\hline Attended day care centre in the first $12 \mathrm{~m}$ & $412(41.04 \%)$ & $304(45.65 \%)$ & $298(44.81 \%)$ \\
\hline Bayley-III raw score (mean(SD)) & 71.14(4.12) & $71.18(3.95)$ & $71.35(3.92)$ \\
\hline Bayley-III scaled score (mean(SD)) & $10.76(2.08)$ & $10.79(2.04)$ & $10.9(2.02)$ \\
\hline Internalising behaviour(mean(SD)) & $41.58(9.19)$ & $41.78(9.09)$ & $41.68(9.14)$ \\
\hline Externalising behaviour(mean(SD)) & $44.90(9.26)$ & $44.83(9.02)$ & $44.82(9.20)$ \\
\hline Age at 2-year interview (years) (mean(SD)) & $2.45(0.14)$ & $2.45(0.14)$ & $2.45(0.14)$ \\
\hline
\end{tabular}

Note: bolded type indicates a $\mathrm{p}<0.05$ difference between the inception cohort and the individual cohorts 
Table 2: The relationship between factors influencing external microbial exposure and cognition and behaviour

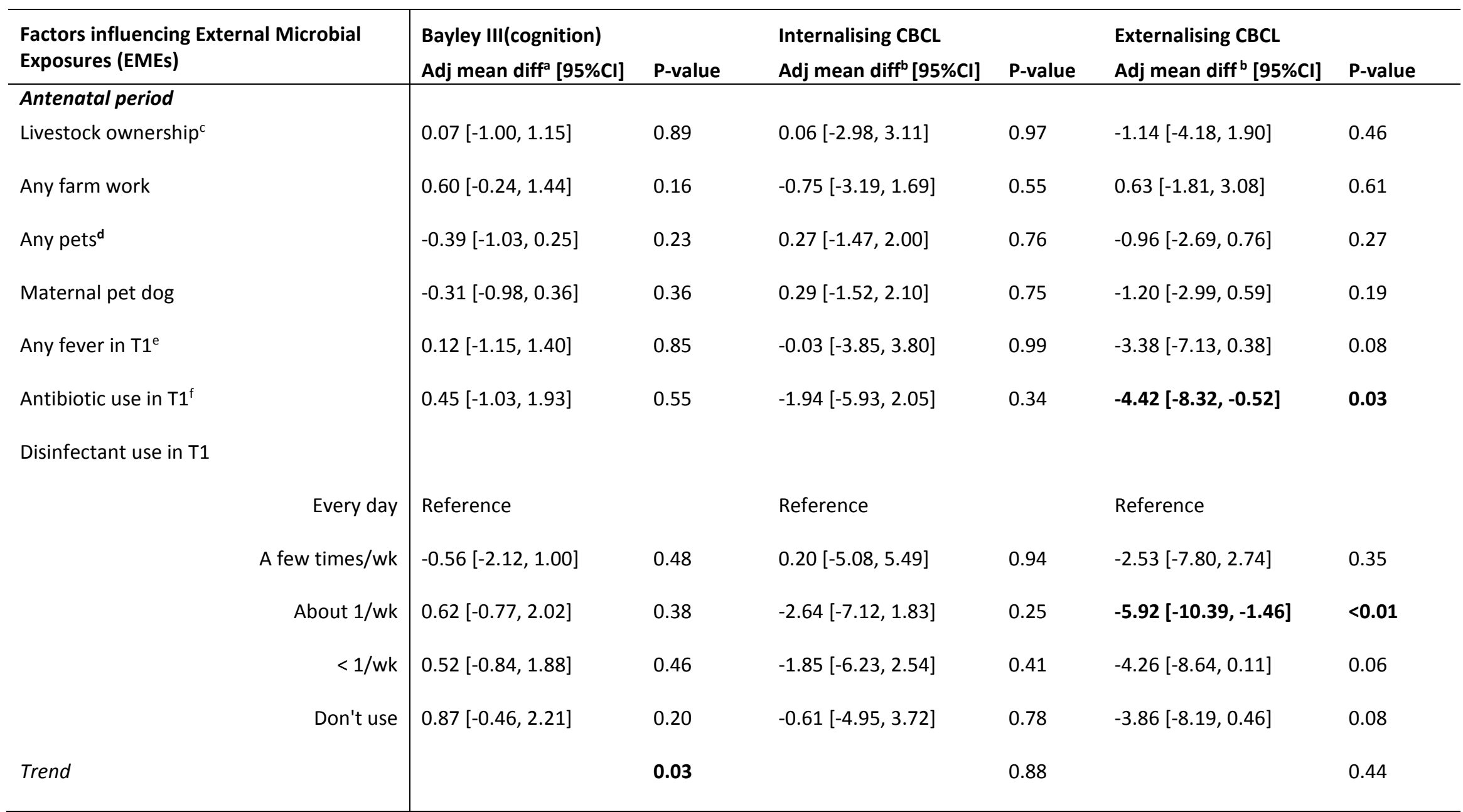

This article is protected by copyright. All rights reserved. 


\begin{tabular}{|c|c|c|c|c|c|c|}
\hline $\begin{array}{l}\text { Factors relating to External Microbial } \\
\text { Exposures (EMEs) }\end{array}$ & $\begin{array}{l}\text { Bayley III(cognition) } \\
\text { Adj mean diff }[95 \% \mathrm{Cl}]\end{array}$ & P-value & $\begin{array}{l}\text { Internalising } \mathrm{CBCL} \\
\text { Adj mean diff }[95 \% \mathrm{Cl}]\end{array}$ & P-value & $\begin{array}{l}\text { Externalising } \mathrm{CBCL} \\
\text { Adj mean diff }{ }^{\mathrm{C}}[95 \% \mathrm{Cl}]\end{array}$ & P-value \\
\hline \multicolumn{7}{|l|}{ Disinfectant use in T2 } \\
\hline Every day & Reference & & Reference & & Reference & \\
\hline A few times/wk & $-0.02[-1.56,1.53]$ & 0.98 & $0.73[-4.38,5.84]$ & 0.78 & $-1.53[-6.68,3.61]$ & 0.56 \\
\hline About 1/wk & $0.82[-0.58,2.22]$ & 0.25 & $-3.14[-7.54,1.27]$ & 0.16 & $-6.92[-11.35,-2.48]$ & $<0.01$ \\
\hline$<1 /$ wk & $0.78[-0.58,2.15]$ & 0.26 & $-2.64[-6.94,1.66]$ & 0.23 & $-5.26[-9.59,-0.93]$ & 0.02 \\
\hline Don't use & $0.89[-0.45,2.22]$ & 0.19 & $0.22[-4.01,4.45]$ & 0.92 & $-3.70[-7.96,0.57]$ & 0.09 \\
\hline Trend & & 0.09 & & 0.50 & & 0.45 \\
\hline \multicolumn{7}{|l|}{ Disinfectant use in T3 } \\
\hline Every day & Reference & & Reference & & Reference & \\
\hline A few times/wk & $0.99[-0.86,2.84]$ & 0.29 & $7.43[0.67,14.19]$ & 0.03 & $5.84[-0.89,12.58]$ & 0.09 \\
\hline About 1/wk & $2.51[0.73,4.28]$ & $<0.01$ & $5.32[-1.18,11.83]$ & 0.11 & $4.20[-2.27,10.68]$ & 0.20 \\
\hline$<1 /$ wk & $2.44[0.72,4.17]$ & $<0.01$ & $6.10[-0.26,12.46]$ & 0.06 & $5.06[-1.27,11.39]$ & 0.12 \\
\hline Don't use & $2.34[0.56,4.12]$ & $<0.01$ & $5.40[-1.08,11.89]$ & 0.10 & $3.52[-2.94,9.98]$ & 0.28 \\
\hline Trend & & $<0.01$ & & 0.96 & & 0.73 \\
\hline
\end{tabular}

This article is protected by copyright. All rights reserved. 


\begin{tabular}{|c|c|c|c|c|c|c|}
\hline \multirow{2}{*}{$\begin{array}{l}\text { Factors relating to External Microbial } \\
\text { Exposures (EMEs) }\end{array}$} & \multicolumn{2}{|l|}{ Bayley III(cognition) } & \multicolumn{2}{|l|}{ Internalising CBCL } & \multicolumn{2}{|l|}{ Externalising CBCL } \\
\hline & Adj mean diff $[95 \% \mathrm{Cl}]$ & P-value & Adj mean diff $[95 \% \mathrm{Cl}]$ & P-value & Adj mean diff ${ }^{c}[95 \% \mathrm{Cl}]$ & P-value \\
\hline \multicolumn{7}{|l|}{ Total no. of adults at home (T1T2) } \\
\hline One & Reference & & Reference & & Reference & \\
\hline Two & $0.84[-1.33,3.01]$ & 0.45 & $-2.74[-8.18,2.71]$ & 0.32 & $-2.39[-7.9,3.11]$ & 0.39 \\
\hline Four or more & $-1.46[-4.5,1.58]$ & 0.35 & $-5.97[-13.79,1.84]$ & 0.13 & $-2.78[-10.69,5.12]$ & 0.49 \\
\hline Trend & & 0.42 & & 0.98 & & 0.80 \\
\hline \multicolumn{7}{|l|}{ Total no. of children at home (T1T2) } \\
\hline None & Reference & & Reference & & Reference & \\
\hline One & $-0.34[-0.97,0.29]$ & 0.28 & $-3.75[-5.47,-2.02]$ & $<0.001$ & $0.16[-1.58,1.90]$ & 0.86 \\
\hline Two & $-1.45[-2.28,-0.62]$ & $<0.001$ & $-4.13[-6.34,-1.91]$ & $<0.001$ & $0.60[-1.64,2.84]$ & 0.60 \\
\hline Three & $-1.58[-3.25,0.08]$ & 0.06 & $-3.05[-7.85,1.76]$ & 0.21 & $2.65[-2.22,7.51]$ & 0.29 \\
\hline Five or more & $-2.36[-5.11,0.40]$ & 0.09 & $-3.88[-13.02,5.27]$ & 0.41 & $2.46[-6.80,11.71]$ & 0.60 \\
\hline Trend & & $<0.001$ & & $<0.001$ & 0.31 & \\
\hline
\end{tabular}

This article is protected by copyright. All rights reserved. 


\begin{tabular}{|c|c|c|c|c|c|c|}
\hline $\begin{array}{l}\text { Factors relating to External Microbial } \\
\text { Exposures (EMEs) }\end{array}$ & $\begin{array}{l}\text { Bayley III(cognition) } \\
\text { Adj mean diff }{ }^{\mathrm{b}}[95 \% \mathrm{Cl}]\end{array}$ & P-value & $\begin{array}{l}\text { Internalising } \mathrm{CBCL} \\
\text { Adj mean diff }[95 \% \mathrm{Cl}]\end{array}$ & P-value & $\begin{array}{l}\text { Externalising } \mathrm{CBCL} \\
\text { Adj mean diff }{ }^{\mathrm{C}}[95 \% \mathrm{Cl}]\end{array}$ & P-value \\
\hline \multicolumn{7}{|l|}{ Birth } \\
\hline \multicolumn{7}{|l|}{ Mode of birth } \\
\hline Scheduled C-section & Reference & & Reference & & Reference & \\
\hline Instrumental vaginal deliveryg & $-0.03[-0.97,0.90]$ & 0.94 & $3.76[1.50,6.02]$ & $<0.001$ & $1.56[-0.73,3.85]$ & 0.18 \\
\hline Unassisted vaginal delivery & $0.17[-0.65,0.99]$ & 0.68 & $2.17[0.20,4.13]$ & 0.03 & $1.36[-0.63,3.35]$ & 0.18 \\
\hline Group B Streptococcus (GBS) & $-0.27[-0.98,0.44]$ & 0.45 & $1.81[-.013,3.75]$ & 0.07 & $1.34[-.60,3.29]$ & 0.18 \\
\hline \multicolumn{7}{|l|}{ Postnatal period } \\
\hline Any Breastfeeding & $3.20[0.23,6.17]$ & 0.04 & $1.37[-4.49,7.23]$ & 0.65 & $1.28[-4.53,7.09]$ & 0.67 \\
\hline \multicolumn{7}{|l|}{ Breastfeeding duration } \\
\hline $0<1 w k$ & Reference & & Reference & & Reference & \\
\hline$\geq 1 \mathrm{wk}<6 \mathrm{~m}$ & $0.20[-1.49,1.88]$ & 0.82 & $-2.56[-6.74,1.62]$ & 0.23 & $-1.83[-5.99,2.33]$ & 0.39 \\
\hline$\geq 6 m$ & $1.05[-0.60,2.70]$ & 0.21 & $-1.47[-5.50,2.56]$ & 0.48 & $-1.86[-5.87,2.15]$ & 0.36 \\
\hline Trend & & 0.005 & & 0.64 & & 0.56 \\
\hline
\end{tabular}

This article is protected by copyright. All rights reserved. 


\begin{tabular}{|c|c|c|c|c|c|c|}
\hline $\begin{array}{l}\text { Factors relating to External Microbial } \\
\text { Exposures (EMEs) }\end{array}$ & $\begin{array}{l}\text { Bayley III(cognition) } \\
\text { Adj mean diff }[95 \% \mathrm{Cl}]\end{array}$ & P-value & $\begin{array}{l}\text { Internalising } \mathrm{CBCL} \\
\text { Adj mean diff }[95 \% \mathrm{Cl}]\end{array}$ & P-value & $\begin{array}{l}\text { Externalising } \mathrm{CBCL} \\
\text { Adj mean diff }{ }^{\mathrm{C}}[95 \% \mathrm{Cl}]\end{array}$ & P-value \\
\hline Infant pet dog & $-0.16[-0.75,0.42]$ & 0.59 & $-0.36[-1.95,1.23]$ & 0.66 & $-1.57[-3.16,0.02]$ & 0.05 \\
\hline Any antibiotic use between $3 \mathrm{~m}-6 \mathrm{~m}^{\mathrm{h}}$ & $0.41[-0.52,1.35]$ & 0.39 & $-3.06[-5.55,-0.56]$ & 0.02 & $-0.53[-3.02,1.96]$ & 0.67 \\
\hline Total antibiotic days to $12 \mathrm{~m}^{\mathrm{i}}$ & $0.02[-0.01,0.05]$ & 0.27 & $-0.01[-0.09,0.07]$ & 0.82 & $0.04[-0.04,0.12]$ & 0.33 \\
\hline Wash hands with sanitiser & Reference & & Reference & & Reference & \\
\hline Wash hands with soap & $0.22[-0.39,0.83]$ & 0.48 & $0.37[-1.32,2.06]$ & 0.67 & $0.26[-1.42,1.94]$ & 0.76 \\
\hline Wipe hands only & $1.68[-0.15,3.51]$ & 0.07 & $-1.52[-6.99,3.95]$ & 0.59 & $2.96[-2.50,8.42]$ & 0.29 \\
\hline Rinse with water only & $-0.55[-2.03,0.92]$ & 0.46 & $-0.31[-4.73,4.10]$ & 0.89 & $-0.46[-4.87,3.95]$ & 0.84 \\
\hline Don't clean hands & $-0.02[-3.02,2.97]$ & 0.99 & $3.23[-5.09,11.54]$ & 0.45 & $1.61[-6.69,9.91]$ & 0.70 \\
\hline \multicolumn{7}{|l|}{ Infant handwashing freq. at $4 \mathrm{wks}^{\mathrm{k}}$} \\
\hline 5 or more times/d & Reference & & Reference & & Reference & \\
\hline $3-4$ times/d & $1.43[-1.10,3.97]$ & 0.27 & $-2.98[-9.59,3.63]$ & 0.38 & $-4.57[-11.15,2.00]$ & 0.17 \\
\hline $1-2$ times/d & $1.64[-0.49,3.77]$ & 0.13 & $-4.43[-9.84,0.98]$ & 0.11 & $-5.66[-11.04,-0.28]$ & 0.04 \\
\hline Not at all & $1.34[-0.80,3.48]$ & 0.22 & $-5.19[-10.62,0.25]$ & 0.06 & $-5.19[-10.60,0.21]$ & 0.06 \\
\hline Trend & & 0.99 & & 0.05 & & 0.40 \\
\hline
\end{tabular}

This article is protected by copyright. All rights reserved. 


\begin{tabular}{|c|c|c|c|c|c|c|}
\hline \multirow{2}{*}{$\begin{array}{l}\text { Factors relating to External Microbial } \\
\text { Exposures (EMEs) }\end{array}$} & \multicolumn{2}{|l|}{ Bayley III(cognition) } & \multicolumn{2}{|l|}{ Internalising $\mathrm{CBCL}$} & \multicolumn{2}{|l|}{ Externalising CBCL } \\
\hline & Adj mean diff' $[95 \% \mathrm{Cl}]$ & P-value & Adj mean diff' $[95 \% \mathrm{Cl}]$ & P-value & Adj mean diff ${ }^{c}[95 \% \mathrm{Cl}]$ & P-value \\
\hline \multicolumn{7}{|l|}{ Infant handwashing frequency at $12 \mathrm{~m}$} \\
\hline 5 or more times/d & Reference & & Reference & & Reference & \\
\hline 3-4 times/d & $-0.06[-0.73,0.60]$ & 0.85 & $0.07[-1.70,1.85]$ & 0.93 & $-0.46[-2.25,1.33]$ & 0.61 \\
\hline $1-2$ times/d & $0.01[-0.88,0.89]$ & 0.99 & $2.99[0.67,5.31]$ & 0.01 & $2.54[0.20,4.89]$ & 0.03 \\
\hline Not at all & $-2.11[-7.30,3.07]$ & 0.42 & $6.39[0.18,12.60]$ & 0.04 & $-0.29[-6.56,5.97]$ & 0.93 \\
\hline Trend & & 0.86 & & 0.03 & & 0.08 \\
\hline \multicolumn{7}{|l|}{ Infant bathing frequency at $6 \mathrm{~m}^{\prime}$} \\
\hline Once or more a day & Reference & & Reference & & Reference & \\
\hline Several times a wk & $-0.63[-1.23,-0.04]$ & 0.04 & $0.07[-1.53,1.67]$ & 0.93 & $1.56[-0.03,3.14]$ & 0.05 \\
\hline Once a wk or less & $-0.80[-2.40,0.81]$ & 0.33 & $3.30[-1.39,7.99]$ & 0.17 & $5.21[0.56,9.85]$ & 0.03 \\
\hline Trend & & 0.03 & & 0.48 & & 0.01 \\
\hline Dummy use at $4 w k s$ & $-0.66[-1.25,-0.08]$ & 0.03 & $0.44[-1.16,2.04]$ & 0.59 & $0.59[-1.00,2.18]$ & 0.46 \\
\hline Length dummy use at 4 wks (hrs/day) ${ }^{m}$ & $-0.14[-0.26,-0.01]$ & 0.03 & $-0.10[-0.49,0.28]$ & 0.60 & $-0.16[-0.55,0.23]$ & 0.41 \\
\hline
\end{tabular}

This article is protected by copyright. All rights reserved. 


\begin{tabular}{|c|c|c|c|c|c|c|}
\hline $\begin{array}{l}\text { Factors relating to External Microbial } \\
\text { Exposures (EMEs) }\end{array}$ & $\begin{array}{l}\text { Bayley III(cognition) } \\
\text { Adj mean diff }{ }^{b}[95 \% \mathrm{Cl}]\end{array}$ & P-value & $\begin{array}{l}\text { Internalising } \mathrm{CBCL} \\
\text { Adj mean diff }[95 \% \mathrm{Cl}]\end{array}$ & P-value & $\begin{array}{l}\text { Externalising } \mathrm{CBCL} \\
\text { Adj mean diff }{ }^{\mathrm{C}}[95 \% \mathrm{Cl}]\end{array}$ & P-value \\
\hline \multicolumn{7}{|l|}{ Method of dummy cleaning at $4 \mathrm{wks}$} \\
\hline Sterilizing agent & Reference & & Reference & & Reference & \\
\hline Wash boiling water & $0.55[-0.43,1.54]$ & 0.27 & $1.38[-1.44,4.21]$ & 0.34 & $2.02[-0.81,4.86]$ & 0.16 \\
\hline Own mouth & $1.08[-0.22,2.37]$ & 0.10 & $3.98[0.17,7.79]$ & 0.04 & $3.27[-0.56,7.09]$ & 0.09 \\
\hline W/o washing & $1.66[-0.18,3.51]$ & 0.08 & $4.45[-1.34,10.24]$ & 0.13 & $5.04[-0.77,10.85]$ & 0.09 \\
\hline Dummy use at $6 \mathrm{~m}$ & $-0.96[-1.54,-0.38]$ & $>0.01$ & $0.21[-1.38,1.80]$ & 0.80 & $0.41[-1.17,1.99]$ & 0.61 \\
\hline \multicolumn{7}{|l|}{ Method of dummy cleaning at $6 \mathrm{~m}^{n}$} \\
\hline Sterilizing agent & Reference & & Reference & & Reference & \\
\hline Wash boiling water & $-0.29[-1.78,1.20]$ & 0.70 & $1.19[-2.99,5.36]$ & 0.58 & $-1.64[-6.02,2.73]$ & 0.46 \\
\hline Wash tap water & $0.51[-0.97,2.00]$ & 0.50 & $2.41[-1.62,6.45]$ & 0.24 & $1.75[-2.48,5.97]$ & 0.42 \\
\hline Own mouth & $1.22[-0.39,2.83]$ & 0.14 & $4.76[0.23,9.28]$ & 0.04 & $3.87[-0.88,8.61]$ & 0.11 \\
\hline W/o washing & $0.72[-0.86,2.30]$ & 0.37 & $0.98[-3.44,5.40]$ & 0.66 & $0.62[-4.01,5.26]$ & 0.79 \\
\hline Dummy use at $12 \mathrm{~m}$ & $-0.60[-1.18,-0.02]$ & 0.04 & $-0.86[-2.45,0.72]$ & 0.28 & $-0.60[-2.20,0.99]$ & 0.46 \\
\hline Any formal child care to $12 \mathrm{~m}^{\circ}$ & $0.68[0.12,1.24]$ & 0.02 & $-1.17[-2.74,0.39]$ & 0.14 & $-1.26[-2.82,0.29]$ & 0.11 \\
\hline
\end{tabular}

${ }^{a}$ adjusted for age at BAYLEY-III interview, child sex, researcher and research assistant experience in administering the BAYLEY-III.

${ }^{\mathrm{b}}$ adjusted for age at interview and child sex.

This article is protected by copyright. All rights reserved. 
${ }^{\mathrm{c}}$ No association was found with chicken, cow, sheep, horse ownership.

${ }^{\mathrm{d}}$ No association was found with whether the pets were kept inside, outside or both.

e No association was found with fever in T2 or T3.

${ }^{\mathrm{f}}$ No association was found with maternal antibiotic use in T2 or T3

${ }^{\mathrm{g}}$ Forceps or vacuum.

${ }^{\mathrm{h}}$ No association was found with any infant antibiotic use to $4 \mathrm{wks}$, between 4 wks and $3 \mathrm{~m}, 6 \mathrm{~m}$ to $9 \mathrm{~m}, 9 \mathrm{~m}$ to $12 \mathrm{~m}$.

iNo association was found with total number of antibiotic days to 4 wks, between 4 wks and $3 \mathrm{~m}, 3 \mathrm{~m}$ to $6 \mathrm{~m}, 6 \mathrm{~m}$ to $9 \mathrm{~m}$, $9 \mathrm{~m}$ to $12 \mathrm{~m}$.

${ }^{j}$ No association was found with maternal handwashing method at $6 \mathrm{~m}$ or $12 \mathrm{~m}$.

${ }^{\mathrm{k}}$ No association was found with infant hand washing frequency at $4 \mathrm{wks}$.

' No association was found with infant bathing frequency at 4 wks or $12 \mathrm{~m}$.

${ }^{m}$ No association was found with length of dummy use at $6 \mathrm{~m}$ or $12 \mathrm{~m}$.

${ }^{\mathrm{n}}$ No association was found with method of dummy cleaning at $12 \mathrm{~m}$.

${ }^{\circ}$ No association was found with age infant first attended child care (wks) to $12 \mathrm{~m}$. 


\section{University Library}

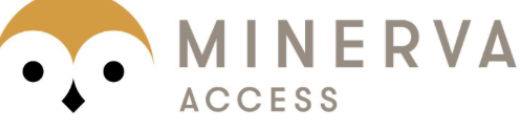

A gateway to Melbourne's research publications

Minerva Access is the Institutional Repository of The University of Melbourne

\section{Author/s:}

Senn, E;Symeonides, C;Vuillermin, P;Ponsonby, A-L;Carlin, J;Tang, M;Collier, F;Dwyer,

T;Ranganathan, S;Sly, P;Harrison, L;Burgner, D

Title:

Early life microbial exposure, child neurocognition and behaviour at 2 years of age: A birth cohort study

Date:

2019-11-29

Citation:

Senn, E., Symeonides, C., Vuillermin, P., Ponsonby, A. -L., Carlin, J., Tang, M., Collier, F., Dwyer, T., Ranganathan, S., Sly, P., Harrison, L. \& Burgner, D. (2019). Early life microbial exposure, child neurocognition and behaviour at 2 years of age: A birth cohort study. JOURNAL OF PAEDIATRICS AND CHILD HEALTH, 56 (4), pp.590-599. https:// doi.org/10.1111/jpc.14695.

Persistent Link:

http://hdl.handle.net/11343/286677 